\title{
"My Preference would be to be at Home": Patient's Experiences of their Hospice at Home Care
}

\section{Elizabeth McKay ${ }^{*}$, Ann Taylor and Claire Armstrong}

Brunel University London, UK

"Corresponding author: Elizabeth McKay, PhD, Brunel University, London, UK, Tel: 441895268754; E-mail: elizabeth.mckay@brunel.ac.uk

Received date: Jul 07, 2014, Accepted date: Sep 15, 2014, Published date: Sep 25, 2014

Copyright: () 2014 McKay E, et al. This is an open-access article distributed under the terms of the Creative Commons Attribution License, which permits unrestricted use, distribution, and reproduction in any medium, provided the original author and source are credited.

\begin{abstract}
A specialist 'Hospice at Home' (HaH) service commenced in 2006 in Mid West Ireland whereby participants received palliative care from a specialist team in their own home. An independent team was commissioned to evaluate the key stakeholders' perspectives of this service including patients, carers and staff. This original paper presents the findings from the patients receiving the $\mathrm{HaH}$ service.
\end{abstract}

Objective: The investigation aimed to examine the experiences of patients receiving Hospice at Home care from a new multidisciplinary palliative care team.

Method: Possible participants were drawn from the clinical register and screened for suitability. Fifteen participants were selected and interviewed using a semi-structure interview schedule; interviews were transcribed and subjected to thematic analysis.

Results: Overall, participants' experiences of the service were positive with quality of care being highly rated. Participants regarded the service as supportive and responsive, particularly in relation to pain management and symptoms. Excellent communication and interpersonal skills from Hospice at Home staff members were highlighted. Overall, participants rated their own quality of life as high; although this cannot be attributed to the HaH service alone. Although not explicitly asked about the possibility of being a burden to family remains an issue for those being cared for at home. The majority of participants were very satisfied with the service enabling them to be cared for at home. Areas for future improvements to the $\mathrm{HaH}$ service emerged, including discussions about advanced care directives, access and method of referral to the Hospice at Home service and patients' understanding of the service being delivered.

Conclusion: The Hospice at Home Service supported participants in facilitating their choice to be care for and to die at home. However, discussion with patients, family and $\mathrm{HaH}$ staff is recommended concerning place of death and the range of services provided by the $\mathrm{HaH}$.

Keywords: Participant's perspectives; Hospice; Home care; End of life care

\section{Introduction}

There is growing evidence that the majority of people with a terminal illness would prefer to be cared for and die at home [1-7]. As a result, increasing the options available for patients to be supported in their choices to die at home is central to the national policy initiatives e.g. the Department of Health (UK), [1] and the National Advisory Committee on Palliative Care in Ireland [8]

Research indicates that the most significant factor in allowing people to be cared for and/or die at home is the provision of specialist palliative care in the community [9]. In Ireland, palliative care is described as:

The continuing active total care of patients and their families at a time when the medical expectation is no longer cure. Palliative care responds to physical psychological, social and spiritual needs, and extends to support in bereavement. The goal of palliative care is the highest possible quality of life for both patient and family [8].
The Hospice at Home $(\mathrm{HaH})$ concept is relatively new to Ireland and the service which is the focus of this study was the first to be offered within the country. Previously people were cared for at home with limited support for carers or admitted for end of life care to a hospice/hospital. The HaH service is based within a Care Centre which provides a comprehensive range of palliative care services in the MidWest Ireland and as recommended the service consists of a multidisciplinary team trained in specialist palliative care [10]. This care centre is funded via Health Service Executive (HSE) and charitable donations. It provides a range of services including palliative care and elderly care. The $\mathrm{HaH}$ Project was a substantial enhancement of these services and offers a range of specialist palliative care services delivered in a community setting by a Multidisciplinary Specialist Palliative Care Team, supported by consultants in palliative medicine. Nursing staff form the largest professional group, along with, social workers, physiotherapists, occupational therapists, pastoral care staff and clerical support. This service aims to provide care over seven days per week. The service can be accessed through internal referrals within the Care Centre and externally from the HSE primary care team, acute hospitals and other service providers. This affords participants and their carers/families access to disciplines to assess and 
manage the physical, emotional, psychosocial and spiritual dimensions of their illness. They also support and provide education and information to family and professional staff through collaboration with the primary care and acute hospital specialists.

Research was undertaken to evaluate this new $\mathrm{HaH}$ service, the first in Ireland, with the aim of examining whether it offered a viable and effective model for delivering a range of palliative care services to patients, their families/carers, members of the service and the wider community [11].This study examines the delivery of a service through a single agency; findings will have implications for this service and others who are providing similar services. The perspectives of bereaved and current carers is reported elsewhere [12]. To date there is only limited research on the voices of those receiving either end of life care or hospice care, two earlier studies one Canadian and one Australian [13,14] focus on particular aspects of dying, including quality of life, carer burden and relationships. A recent UK study examined what people want at the end of their life and reported $63 \%$ of people want to die at home, however, this study did not include the voices of patients being cared for in their homes [15].

This original paper presents the patients' perspectives; as service users of the first $\mathrm{HaH}$ service within Ireland, in terms of how it supports their choice to be cared for and die at home. Including the perspectives of service users is a feature of new services within the Irish healthcare system and is an important means of promoting 'services that are safer, more accessible and of a higher quality' [16]. Moreover, by involving the patients, it recognises them as experts by experience.

\section{Methodology}

This research was approved by the local Mid-Western Research Ethics Committee and written consent was obtained from all participants. The vulnerability of participants undergoing palliative care is a major issue in conducting research with this group of people $[17,18]$. Involving users in the evaluation of a service poses a number of challenges for services, particularly when devising strategies to involve individuals who are ill and/or vulnerable and to ensure that the conditions of involvement are in proportion to service users' abilities. This is of particular relevance for this study which involved interviewing participants with regard to end-of-life issues whilst being cared for in their own homes.

Research within palliative care can be challenging. Roscoe et al. [19] remind us that it can be methodologically complex as some participants and their families wish to concentrate on their remaining time together rather than being participants in research. Therefore, to be sensitive to this dynamic; semi-structured interviews were chosen to examine the provision of care at the end of life through the $\mathrm{HaH}$ service. The interview schedule covered a set of open-ended questions which were divided into a number of themes relating to quality indicators of care including: 'Quality of Care, Information and Communication; Management of Symptoms; Access to the Hospice at Home Service and Choice of Care (e.g. timing of referral to the service and preferred pre-death location); and Psychosocial Support'. Participants were offered an opportunity to identify any additional areas that they perceived as impacting on the quality of care they received, to recommend ways in which improvements could be made and to rate the overall quality of the service. Interview duration was determined by the interviewees and ranged from 15 to 45 minutes. Without tiring the participant, the interviewer at times repeated questions in different ways to facilitate recall of information and confirm the accuracy of the information.

The interviews were digitally recorded and transcribed verbatim. Thematic analysis was undertaken to ascertain the prevalence of issues in line with the evaluation of the quality of care indicators.

\section{Participants}

Patients were referred to the $\mathrm{HaH}$ service primarily via their General Practitioner and the Care Centre in which it is based. As highlighted above, the selection and sampling process in relation to this patient group posed a number of challenges due to the nature of the population; those receiving palliative care at home are vulnerable and unpredictable subjects due to the nature of their condition. In this regard, the importance of assessing patients' records who were receiving the service was emphasised to ensure that no name on the research sample list related to patients who may have died since the list was compiled or who were too unwell or frail to participate in the study. The inclusion and exclusion criteria for eligible participants are outlined in Tables 1 and 2 below.

\begin{tabular}{|l|}
\hline INCLUSION CRITERIA for Participants \\
\hline Currently receiving the Hospice at Home Service \\
\hline Adult English speaking \\
\hline $\begin{array}{l}\text { Ability to sustain effort for the interview as assessed by the Hospice at Home } \\
\text { link professional }\end{array}$ \\
\hline Provision of documented informed consent \\
\hline
\end{tabular}

Table 1: Inclusion Criteria for Participants

\section{EXCLUSION CRITERIA for Participants}

The participant had an excessive symptom burden at the proposed time of interview

The participant was actively dying, based on clinical judgement

The participant was confused or otherwise cognitively impaired, based on clinical judgement

There was an identifiable known severe mental health issue in the participant/ carer/family which meant that participation in research could impact on their well-being, based on clinical judgement

There was an unrelated family crisis at the proposed time of interview

There was an excessive level of risk to the researcher, e.g. Mental health/ substance misuse issues of participant/family, family living in a known high-risk locality or any other issue that would pose a high risk to the researcher's personal safety

The participant had been discharged from the Hospice at Home service

The participant was unaware that they were receiving palliative services

Participant had already been targeted for previous research

Table 2: Exclusion Criteria for Participants

Over the summer of 2010, all 129 clients' records were reviewed. Following this screening for eligibility by the clinical nurse specialist or social worker, 93 patients were eliminated by the exclusion criteria. This left 36 possible participants who met the inclusion criteria. They 
Page 3 of 7

were invited to participate by a letter which was issued by the $\mathrm{HaH}$ staff. The letter contained information on the evaluation and the role of the interviewer. Three people declined to participate and the remaining 33 possible participants were contacted to arrange a convenient time to be interviewed. However, eighteen participants became unsuitable as their health deteriorated before the interviews could be arranged/completed. Therefore the selection process produced a final cohort of fifteen participants.

In the majority of cases, interviews were conducted in the participants' homes with two interviews being held at the Care Centre for convenience.

\section{Findings}

The demographic and illness characteristics of the people who participated in this study are outlined in Table 3. This sample was not intentionally stratified by gender, marital status, race, religion or primary diagnosis. Over half of the participants (53\%) were aged between 55 and 74 years of age. Approximately two thirds of the participants were married or in a relationship (67\%), were predominantly Irish and from Christian denominations. The majority of participants' primary diagnosis was some form of cancer (87\%).

\begin{tabular}{|c|c|c|c|}
\hline $\begin{array}{l}\text { PROFILE } \\
\text { FEATURES }\end{array}$ & $(N=15)$ & $\begin{array}{ll}\text { NUMBER } & \text { OF } \\
\text { RESPONDENTS } & \end{array}$ & $\%$ \\
\hline \multirow[t]{2}{*}{ Gender } & Male & 6 & 40 \\
\hline & Female & 9 & 60 \\
\hline \multirow[t]{2}{*}{ Marital Status } & Married/Partner & 10 & 67 \\
\hline & $\begin{array}{l}\text { Single/Separated/ } \\
\text { Widowed }\end{array}$ & 5 & 33 \\
\hline \multirow[t]{6}{*}{ Age } & $35-44$ Yrs & 2 & 13 \\
\hline & 45-54 Yrs & 2 & 13 \\
\hline & $55-64$ Yrs & 4 & 26 \\
\hline & $65-74$ Yrs & 4 & 26 \\
\hline & $75-84$ Yrs & 2 & 13 \\
\hline & $>85$ Yrs & 1 & 7 \\
\hline \multirow[t]{2}{*}{ Race-ethnicity } & White - Irish & 14 & 93 \\
\hline & White non-Irish & 1 & 7 \\
\hline \multirow[t]{2}{*}{ Spiritual Identity } & Christian & 12 & 80 \\
\hline & Unkn $\rightleftharpoons \mathbb{P}^{\text {Affiliation/ }}$ & 3 & 20 \\
\hline \multirow{2}{*}{$\begin{array}{l}\text { Primary } \\
\text { Diagnosis }\end{array}$} & Cancer & 13 & 87 \\
\hline & Other & 2 & 13 \\
\hline \multirow[t]{3}{*}{ Referral Route } & GP & 3 & 20 \\
\hline & Hospital & 10 & 67 \\
\hline & Unclear/Unknown & 2 & 13 \\
\hline
\end{tabular}

Table 3: Profile of Participants Interviewed

\section{Quality of care}

Overall, when asked about the quality of care provided by the $\mathrm{HaH}$ Service, thirteen of the fifteen interviewees were positive in their responses. Fourteen interviewees stated that their preference was to be cared for at home with the majority of those respondents (11) indicating that their ability to be cared for at home was due primarily to the provision of this Service.

Participants were asked to rate the quality of the overall $\mathrm{HaH}$ service where 1 was poor and 10 was excellent. All of the participants indicated satisfaction with the service to a level of 7 or above, with an average rating of 9 (SD 1.1).

The reasons for low ratings were explored with interviewees. In the case of the lowest rating (7), it was due primarily to their past experience of respite care. Therefore, it could be assumed that the criticism was not of the HaH service itself. For those who rated the service at 8 and above, feedback was positive with no obvious indications of inadequacies. As this respondent stated:

“...could it get better? I don't think it could get better. Really and truly I get great service...” (Participant 006)

The thirteen interviewees who had a nurse as the primary professional involved in their care stated satisfaction with the service and in most cases (11 people) praised the input by the nurses in ensuring their needs were met. Many highlighted the good interpersonal skills of the nursing staff and identified various aspects of these skills in terms of the relationships that had built up between the participant and the nurse. Interviewees also reported on the manner in which staff worked and appreciated that even in situations where staff may have been unsure about advice or did not have the relevant skills to deal with a situation, they had no hesitation to seek additional expertise and resources.

The following reflects the participants' views regarding the quality of the nursing staff:

“...they can be completely matter of fact about it,... they are very sympathetic and they don't make you feel uncomfortable about asking those questions...if they didn't have the answer there and then, they would call me back pretty quickly, so I've never had any problems in getting answers to questions" (Participant 002)

"...helps me with my next respite and like if I had a problem, she would flag it with the doctors.. I'd say she's very honest with me...." (Participant 005)

The service also includes; social workers, occupational therapists, physiotherapists and pastoral care. Only two interviewees stated they had involvement with the social worker, three with the occupational therapist, and three others stated involvement with the physiotherapist. Discussions regarding these services were limited as the input from these professionals appears to be short or infrequent compared to the input by the nursing team. Feedback regarding these other team members was nevertheless positive. Importantly, all the interviewees were able to identify at least one named professional involved in their care.

\section{Information and communication}

Participants identified a range of issues in relation to the communication skills of staff and their satisfaction with the adequacy of information provided. Their responses indicated that a number 
were unclear that the Service was 'hospice care' or that they had been involved in the decision to independently select this Service in the first instance.

When participants were asked about their first home visit experience and whether staff provided relevant information on the service, just over half of interviewees (8) indicated that the information they received was adequate. The remainder, however, stated they did not receive any information, or that the stage in their illness reflected a time of confusion and so they were unsure as to what information was made available to them. These quotes illustrate these experiences.

"Now I wouldn't be too sure of it, but I think probably as well, that when they came out here then they probably told me more." (Participant 006)

"I never found it out until you (interviewer) said it to me. When you asked me about doing this I said to somebody 'what can I tell her about the Hospice? Sure I don't know anything about it except for, there was another chap from xx (participant's local area) who was friendly with my boys and he was in Hospice before he died'. And then I had the idea that when you went into the Hospice that was it. That you went in and you died."

\section{(Participant 001)}

Participants indicated a range of reasons for lack of their knowledge about the service including their health condition; not wishing to know and the difficulty balancing their own needs and those of the family and $\mathrm{HaH}$ team.

"I think I would prefer it that way. I think if I knew too much I might start worrying about myself, and I don't want to. I want to keep a bright face on for the lads here at home anyway."(Participant 011)

"No. I think they made that decision early on for me, the least amount of knowledge the better. .... I'm just not interested, no I am interested but I don't want to know. I'll just take it as it comes." (Participant 012)

In terms of staff being skilled in responding to questions and in ensuring participants were being listened to, all interviewees were positive about staff on a number of levels. Where staff members were unclear about information, they stated that they would ensure that they referred to other professionals for advice and were prompt in communicating the relevant information.

"I mean if they couldn't answer the questions themselves, they would call Dr XX to get advice, and if they didn't have the answer there and then, they would call me back pretty quickly, so I've never had any problems in getting answers to questions." (Participant 002)

“... if there was anything she (nurse) wasn't sure of, she would say "leave it with me", even medication I was on and she wasn't familiar with, she would always either call back or ring me back with answers once she had found out herself." (Participant 004)

The majority (13) of the respondents demonstrated satisfaction in their communication with staff. Many stated that staff members were 'honest' and 'sensitive and listened', that they created a relationship of 'trust' and 'that staff were efficient and effective' when participants were in need of assistance outside their routine appointments. Moreover, for participants whose relatives were their carers, staff members were also seen to be equally responsive to the relatives needs. The following quotes encapsulate the above;
"From the third visit on, I was gabbing away and I trusted her and I knew that she could help me. She didn't always have the answers but she would certainly be able to help me think through things. Sometimes you think about things and you're not able to bring it through to an end, your thought process gets mixed up and so on. But she was very helpful in that regard." (Participant 002)

"Very easy to talk to, very. They must be hand-picked; they're certainly very nice people.” (Participant 009)

However, there were two criticisms that related primarily to communication. One criticism concerned an individual $\mathrm{HaH}$ carer's communication style and the other the use of mobile phones when visiting.

In all other matters, participants indicated they were treated with respect and dignity with each individual's personal circumstances and needs taken into account.

\section{Management of symptoms}

The majority of the interviewees reported satisfaction with the service and staff in relation to their symptom management. The participants stated that for example when they had queries in relation to medication, ses promptly liaised with their GPs or requested GPs to call ditery to the participants to check the medication and symptoms.

Participants reported that when their pain was severe the service responded by arranging for them to be admitted to Care Centre if necessary, until their symptoms were brought under control. For the eleven people, where pain management was relevant, participants identified a range of situations and responses by the service that indicated high levels of satisfaction regarding monitoring of their medication and symptom control. The following reflects some of this feedback:

"Every time they change my tablets, they phone me up to see how I'm going, which I have no problem with at all. Even at the weekend, she rang to check if I was alright, which is good." (Participant 012)

“... A few weeks ago, I felt well and I decided to reduce the Morphine I was on, casually mentioned it to the hospice nurse, and she said 'for God's sake don't do that......' And there have been several of those kind of instances now where I have had the good fortune to be involved with hospice. Those little things, you could say they are only small things, but they are huge things, they make a huge difference to me." (Participant 007)

"Definitely (they organised) the proper pain relief. Yeah, that was the biggest thing. And again it wasn't just handed to you in a bag. You were monitored. I was started on a very low dose and within.... again they couldn't believe it.... I was on the phone after a week saying the pain is coming back. And it was upped and upped until I was at a level where I could go to bed and not feel pain anymore." (Participant 004)

\section{Access to the hospice at home service and choice of \\ The majority of interviewees (11) felt that their referral was at the} appropriate time, only one felt it was 'too early' and the remainder of interviewees were unclear due to confusion or lack of recall at a time of stress related to their illness and diagnosis. One participant stated

"No, no delay. Well, it certainly was early enough, because up to a couple of weeks prior to being introduced to Service I was fine. It was 
only when I started the new drug.....it definitely wasn't too early or too late." (Participant 009)

In response to the preferred place of care, thirteen were positive about their place of care: being at their home; two participants did not express an opinion. The following illustrate their responses:

"Definitely stay at home if my family are able to cope with me emotionally" (Participant 004)

"Until the last minute I would try to stay at home as long as I could...my preference would be to be at home "(Participant 007)

"[Cared for at home] as opposed to being in a hospice? Oh yeah" (Participant 012)

\section{Psychosocial Support}

The term 'psychosocial' support includes care in response to the psychological, social, practical and spiritual needs of the participant, each of which may to some extent be interlinked with each other. Within this general context, indicators of quality for the service are determined by the service's ability to adapt to each individual's circumstance and meet the range of psychosocial needs of participants and their families accordingly.

When asked about psychological needs, most participants indicated that staff members were positive in how they helped them to talk about their concerns.

"It's useful like you can talk over any problems or anything that's going wrong at the present time." (Participant 010)

"She didn't always have the answers but she would certainly be able to help me think through things...Very personal and even apart from the pain relief that sense of just knowing that they were there and they understood me. ...The emotional end of it as well." (Participant 004)

"...it gave me the opportunity to talk to people who were objective to my situation and who weren't family." (Participant 002)

"It is so great to have people around like that who you can talk to. Who on the one hand are very, very nice, but at the same time they are professionals so you are not burdening your friends." (Participant 008)

Seven participants reported that the service was particularly helpful in terms of helping both them and their families at a psychological level. The following is typical of responses regarding support for families.

"They will explain things to my own children if the time comes that I need that. Or, I could ask them for advice.....and they were able to advise me on things to do with my own family, my own children and my husband." (Participant 004)

"...there's help there and if she (wife) has any questions, she can phone them. We're sort of like, one. I'm sick, but there are two of us sick, because my (wife) goes through it all as well." (Participant 012)

In matters relating to social or practical matters, participants stated a number of situations where the services were helpful.

"She did get some things for us though, that we didn't know were available. She got some changes to the house in the very early days, like the bathroom downstairs. Little things like special pillows..." (Participant 005)

Only one participant had availed themselves of the pastoral service and one other stated that she would use it if it was offered. The remainder stated that they were unaware of the service or were adamant that they did not need it. The views are summed up below.

"No. I didn't even know they did anything like that." (Participant 008)

“Not relevant, I am not one bit religious." (Participant 011)

Participants' views of their quality of life were sought. Figure 1 below provides an overview of the results from a rating of 1-7 (where 1 is low and 7 is high) as allocated by each interviewee $(\mathrm{N}=13)$ on their quality of life (responses were not received from two participants).

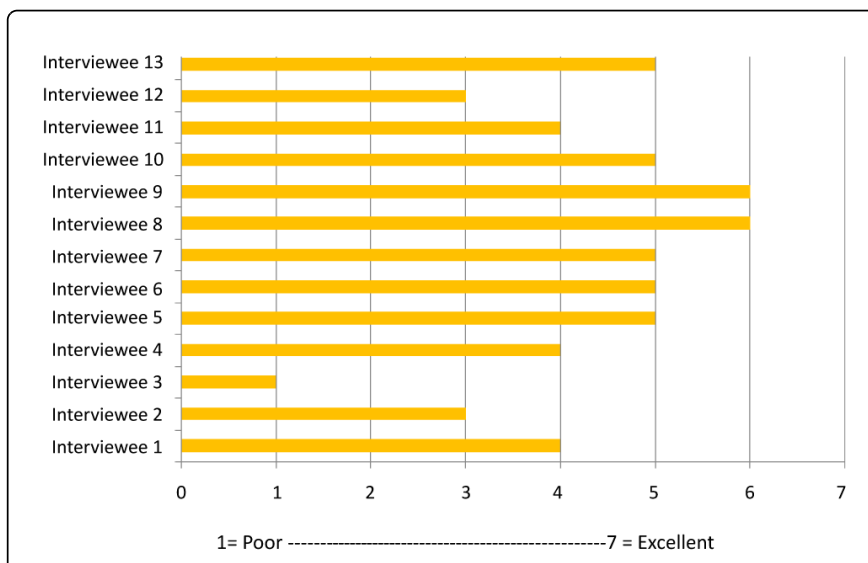

Figure 1: Participants' Perception of their Quality of Life (The average rating was 4.3076 and the standard deviation is 1.3774).

Most of the participants considered they had a reasonable quality of life with (7) rating it as 5/7 or higher and only 1 person rating it a as poor.

\section{Discussion}

What clearly emerged from this research was that the majority of the participants were satisfied with the Hospice at Home service. It enabled them to live and be cared for in their preferred place, which was at home; reflecting recent research that most people which to die at home [15].

Importantly, pain management was well monitored and managed with team members quickly responding to medication changes. It seemed the service was meeting the priority of people to be pain free at the end of their life in line with the findings of the recent UK study [15]. One of the key goals of quality palliative care is management of pain, and this can be difficult, especially in home settings. However, in line with best practice, team members sought specialist advice and gave participants reassurance that the best care in relation to pain management was being provided.

Participants stated they experienced effective and supportive communication. A guiding principle and key standard on quality hospice care is that effective communication is fundamental particularly when it ensures respect and sensitivity for the participant and their family. Participants here were able to identify that one named professional was involved in their care reflecting the key component of best practice in community palliative care.

Dissatisfaction and criticism about care can often be attributed to ineffective communication rather than inadequate service delivery and 
the overall feedback regarding the $\mathrm{HaH}$ Service, even by the participants who voiced criticisms, was positive. It should be noted that as with other user satisfaction studies, a participant's perspective of quality will vary and may be influenced by their relationship with their healthcare staff $[20,21]$.

Providing appropriate and relevant information in response to participants' needs is complex. This is due to a large extent to the difficulties that palliative services face when deciding how and when to provide the information in such a way that the process is sensitive to a participant's ability to receive and understand the information. While services promote an ethos of participant choice and participant participation in decision making, this is highly dependent on adequately informed participants. Furthermore, the ways in which participants are told information and involved in decision-making are important determinants of satisfaction with care [22].

Within this study, it emerged that a number of participants were unclear that they were utilising the hospice at home service, or were unaware of the significance of this for them. This may have been for various reasons but it highlights the need for the $\mathrm{HaH}$ service to address these issues going forward specifically; regarding discussions about place of care, the need for advance directives to be in place and early explanation of the service with the patient in relation to their needs at the time of referral. Nonetheless, in the case of palliative care patients, consideration needs to be given to the amount of information which is conveyed and its timing. For example, terminology such as 'hospice' or 'palliative care' and 'end of life care' conjures up a range of associations and emotions for many people. It is therefore necessary to be sensitive to this and to have discussions about what the service is and what it can provide. Without adequate information and sensitive discussions, potential recipients of the service may have less than positive attitudes to hospice care, they may decline the service and miss out on many of its benefits. The complexity is further accentuated when staff members are under-resourced regarding time, training and expertise in communication on such subjects as death and dying [11].

The considerable importance of psychosocial needs for participants, particularly as death comes nearer, is of great significance for the home-based services and in some studies, it has been found that more emphasis is placed by participants on social rather than physiological needs and on being with family in familiar surrounding (D-23]. Participants here indicated that the involvement with th vice supported them and their family. However, similar to the Canadian and Australian studies $[13,14]$ the worry of becoming a burden was still raised by some and indicates the need for further discussion regarding what other support is available to minimize burden for themselves and their family.

Although, spirituality is cited as being to the forefront of palliative care and an important aspect in helping participants to reduce overall suffering, there was a relatively low prevalence of responses indicating use of the Hospice at Home Pastoral care service and indeed limited knowledge of this aspect of the service. Therefore, again highlighting that the services available require to be explained to patients and their families, to ensure that they are fully aware of what is available to support them.

Whilst this study did not attempt to specifically identify components that contributed to the participants' quality of life it is clear that the majority of the patients considered their lives to be of an overall high quality. Some of the findings presented in this paper suggest an alignment between satisfaction with the $\mathrm{HaH}$ service and quality of life e.g. high satisfaction levels regarding communication on care issues. However, as these have not been formally explored it is not possible to state whether it is a result of the $\mathrm{HaH}$ service.

Enabling participants to choose where they live and die is a fundamental aim of palliative care and a key indicator of quality in hospice services. Care at home is considered by most as their preferred option and signifies for them the ability to retain some form of control over their lives. However, to ensure that the appropriate course of action is followed to meet the participant's preferences, advanced care planning in this regard is crucial. The context in which the person lives means time is an imperative consideration and that without good planning and knowledge of services/resources available, the patient's and carer's choices may not be fully maximised.

In summary, what is evidenced here is that the Hospice at Home Service is person-centred and was valued by participants and meeting their needs. It achieves its goal of enabling people to live and be supported at home and adds to the limited evidence which hears the voices of the dying. This is supported by the key findings of high satisfaction levels in relation to the provision of care and support, communiantipn and interpersonal skills from Hospice at Home staff member 2 timely monitoring and management of symptoms and medication. However, there was a need for continued discussion concerning the meaning of the hospice at home for patients, a review of how information regarding the service is communicated and followed up and importantly, for advance care directives to be implemented as early as possible by the service.

\section{Acknowledgements}

We would like to thank the participants who gave their incredibly valuable time at the end of their lives to make this study possible.

\section{References}

1. Department of Health (2008) End of life care Strategy: Promoting high quality care for all adults at the end of life. Department of Health, London.

2. Davies E and Higginson IJ (2004) Better Palliative care for older people. WHO Regional Office for Europe, Copenhagen.

3. Higginson IJ (2003) Priorities and Preferences for End of Life Care in England, Wales and Scotland, National Council for Hospice and Specialist Palliative Care Services, London.

4. Karlsen S, Addington-Hall J (1998) How do cancer patients who die at home differ from those who die elsewhere? Palliat Med 12: 279-286.

5. Tang ST, McCorkle R (2001) Determinants of place of death for terminal cancer patients. Cancer Invest 19: 165-180.

6. Weafer and Associates (2004) Research with TNS MRBI. (2004) A nationwide survey of public attitudes and experiences regarding death and dying, November, Dublin: Hospice Friendly Hospitals Programme.

7. Wilkinson EK, Salisbury C, Bosanquet N, Franks PJ, Kite S, et al. (1999) Patient and carer preference for, and satisfaction with, specialist models of palliative care: a systematic literature review. Palliat Med 13: 197-216.

8. National Advisory Committee on Palliative Care (2001) Report, Department of Health \& Children: Dublin.

9. Costantini M, Camoirano E, Madeddu L, Bruzzi P, Verganelli E, et al. (1993) Palliative home care and place of death among cancer patients: a population-based study. Palliat Med 7: 323-331.

10. Mid Western Health Board (2004-2011) Seven year Strategic Plan for the Development of Specialist Palliative Care Services ion the Mid West Region. 
Citation: McKay E, Taylor A, Armstrong C (2014) "My Preference would be to be at Home": Patient's Experiences of their Hospice at Home Care. J Palliat Care Med 4: 189. doi:10.4172/2165-7386.1000189

Page 7 of 7

11. McKay EA, Taylor A and Armstrong C (2012) "With comfort, dignity and support" An evaluation of the Hospice at Home service delivered by Milford Care Centre. University of Limerick, Ireland

12. McKay EA, Taylor AE, Armstrong C3 (2013) "What she told us made the world of difference": carers' perspectives on a hospice at home service. J Palliat Care 29: 170-177.

13. McPherson CJ, Wilson KG, Murray MA (2007) Feeling like a burden exploring the perspectives of patients at the end of life. Soc Sci Med 64 417-427.

14. Broom A, Cavenagh J (2011) On the meanings and experiences of living and dying in an Australian hospice. Health (London) 15: 96-111.

15. Wood C, Salter J (2013) A time and a place - want people want at the end of life. Sue Ryder.

16. HSE \& DoHC (2008) National Strategy for Service User Involvement in the Irish Health Service. Health Service Executive: Dublin.

17. Karim K (2000) Conducting research involving palliative patients. Nurs Stand 15: 34-36.
18. Polit DF, Hungler BP (1999) Nursing Research Principles and Methods. Lippincott: Philadelphia.

19. Roscoe LA, Egan KA, Schonwetter RS (2004) Creating an academiccommunity provider partnership in hospice, palliative care, and end-oflife studies. Cancer Control 11: 397-403.

20. Campbell SM, Braspenning J, Hutchinson A, Marshall M (2002) Research methods used in developing and applying quality indicators in primary care. Qual Saf Health Care 11: 358-364.

21. Hibbard JH (2003) Engaging health care consumers to improve the quality of care. Med Care 41: I61-170.

22. Arnold BL (2011) Mapping hospice patients' perception and verbal communication of end-of-life needs: an exploratory mixed methods inquiry. BMC Palliat Care 10: 1.

23. Baker R, Wu AW, Teno JM, Kreling B, Damiano AM, et al. (2000) Family satisfaction with end-of-life care in seriously ill hospitalized adults. J Am Geriatr Soc 48: S61-69. 